\title{
Riolito, o Vulcão Pernambucano
}

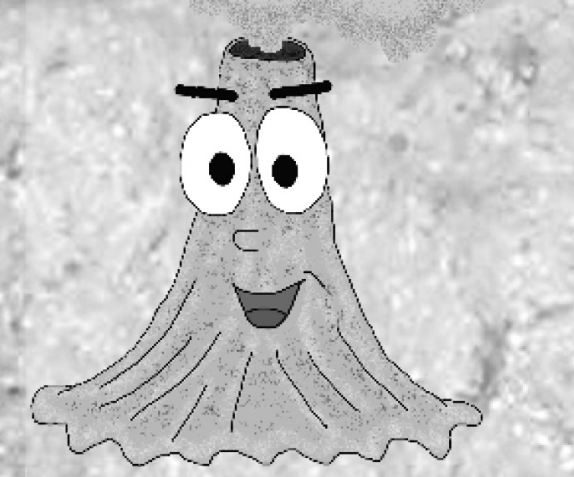

\author{
Texto: Gorki Mariano \\ Desenhos: Antonio Barbosa
}

Para Brian Mariano Derocy

Um pouco da história da Terra

À luz da Geologia

Meu nome é Riolito

Sei que parece esquisito

Mas é assim que me chamam

Desde que chegou o homem

Nas terras onde eu vivia

Em plena e quente alegria

Sou uma rocha, é verdade

E digo com sinceridade

Das mais novas do Brasil.

Nasci quase de repente

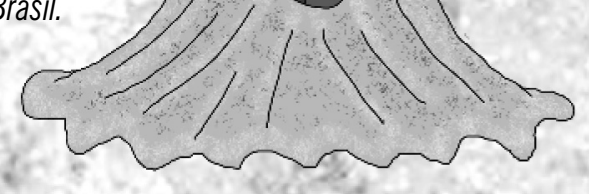

Quando um enorme continente

Com um nome muito bacana

Era um tal de Gondwana

Decidiu fragmentar

Dando origem ao mar

Pois afirmo e não me engano

Nasci junto com um oceano

Nesta época singular

Entre Brasil e África.

Ainda não havia mar 
Quando Gondwana quebrou

A terra movimentou

Os continentes migraram

Como jangadas ao mar

Aos poucos se separaram

Para o Atlântico formar

Com essa abertura

Essa imensa fratura

As rochas das profundezas

Que o nosso planeta encerra

Fundiram e então subiram

Para a superfície da terra

Eu e mais alguns parentes

Aproveitamos a ocasião

E subimos como bolhas

Ou semelhantes a balões Na realidade, pequenos vulcões Quer saber quando foi isso? Eu conto sem embaraço A minha idade não engano Confusão eu nunca faço Este fato aconteceu Há 102 milhões de anos

?

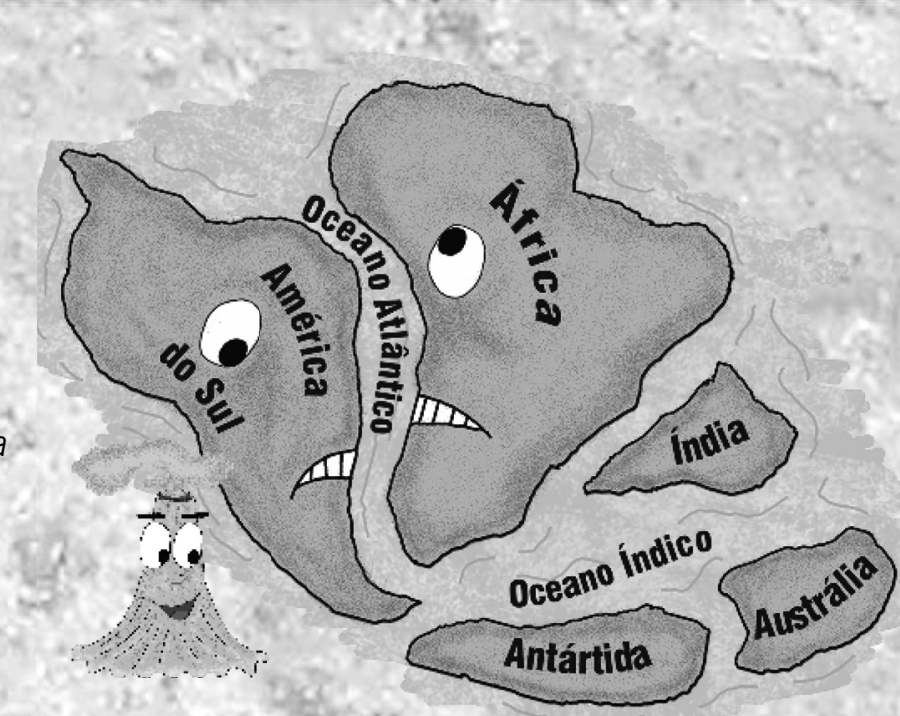

Claro que não havia humanos

Surgiram muito depois Éramos nós, as rochas Que subíamos em profusão

Éramos muitos vulcões
Eu, um Riolito

Me acho o mais bonito E até hoje estou aqui Claro que sem atividade Sem fumaça e sem calor Sem causar dano ou tremor Moro às margens do Ipojuca Perto de uma usina de cana Ao lado de um arruado Já fui um cabra danado Já fundi a minha cuca Chegávamos à superfície Em formato de vulcão Se vocês não sabiam Agora prestem atenção Nas terras de Pernambuco Nesse tempo meio maluco

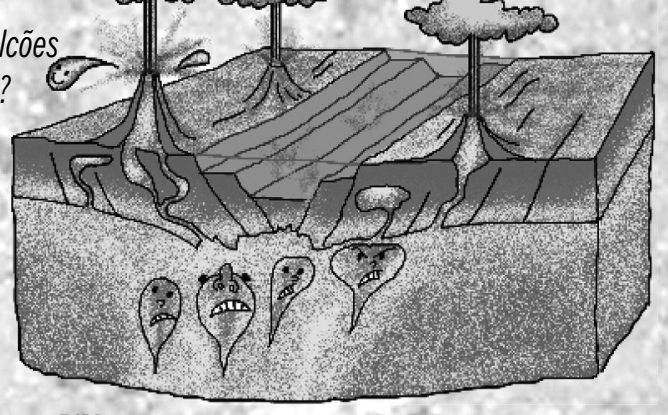

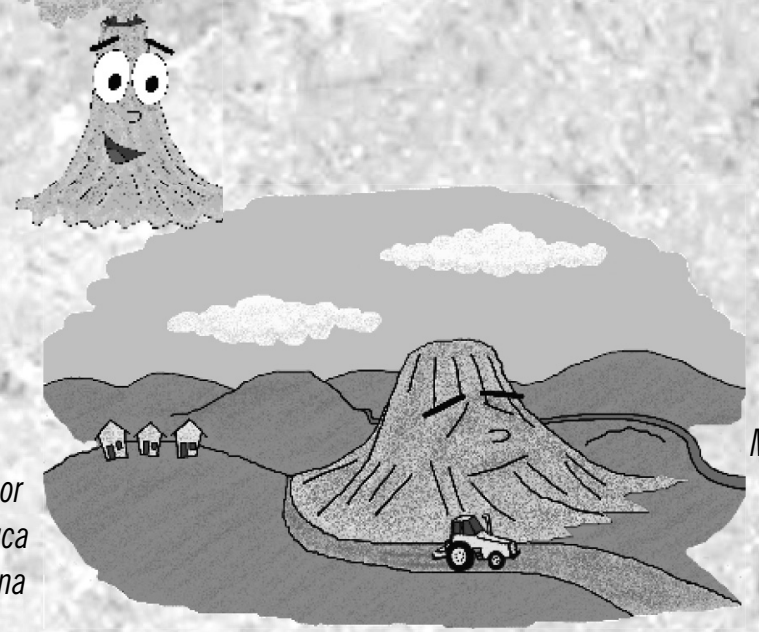

Hoje estou tranqüilo Bebendo do sol o brilho Sendo raro testemunho De que a terra se move Mesmo que alguém reprove Eque até hoje o Brasil Se afasta bem devagar Do continente africano Dando ao oceano Atlântico Mais espaço e lugar 
Mas preciso apresentar Outros membros da família Todos com a mesma idade E seguindo a mesma trilha Na praia de Gaibú Que é bonita ao céu azul Tenho um primo plutônico Formado em profundidade É o Granito do Cabo Que empresta sua beleza Suas areias grossas e pretas Pra Gaibú e Calhetas
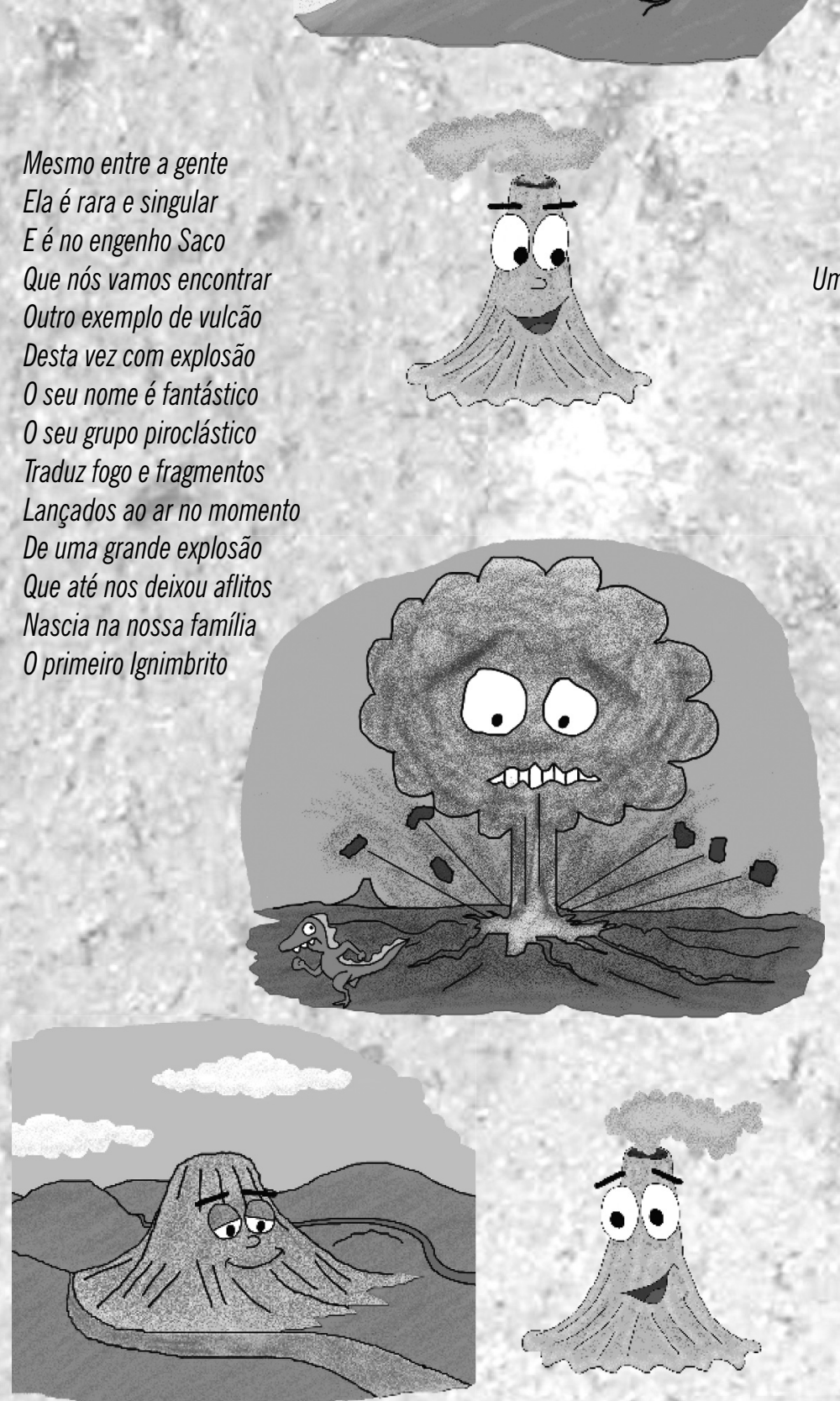

Outros parentes existem Espalhados na região Mas um chama atenção

Pela origem peculiar

Édesse meu parente Que vou começar a falar. Depois que passa a entrada Da praia de Porto de Galinhas Há uma estrada pequena Apertada e bem tortinha Que vai dar em uma pedreira De uma rocha diferente

A família tem mais membros Com alguns nomes esquisitos Dentre estes quero ressaltar Os Basaltos e Traquitos Mas, de longe, em beleza Estou eu, o Riolito Pode vir me visitar Conhecer mais minha história Se não tiver tempo agora Não me incomoda esperar Estou às margens do rio Sou rocha não sinto frio $E$ adoro este lugar. 


\section{Principais ocorrências de}

Rochas Magmáticas na região Costeira de Pernambuco

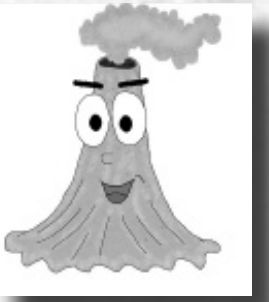

Riolito

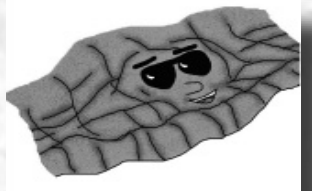

Granito do Cabo de Santo Agostinho

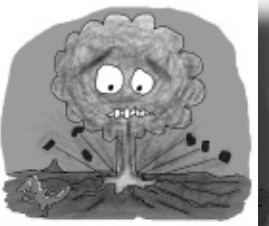

Ignimbrito

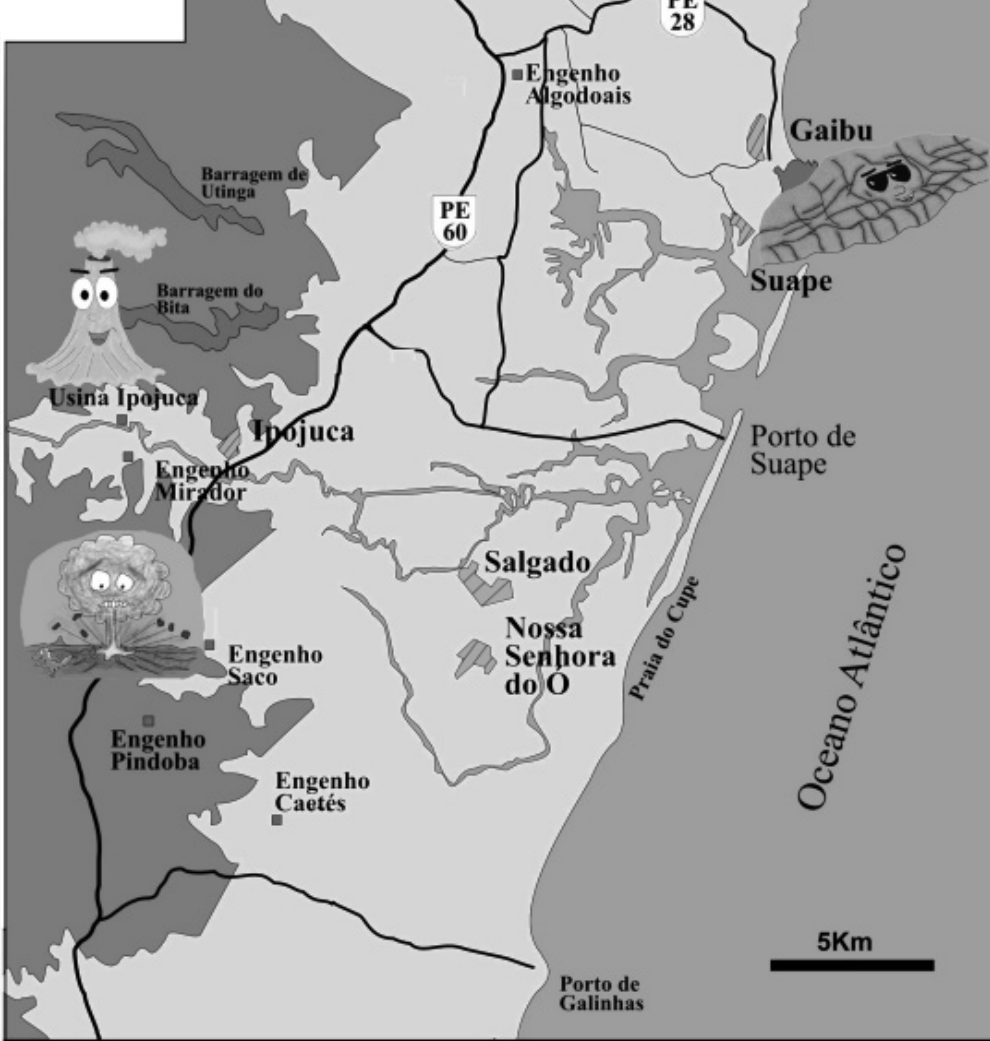

\section{Rochas magmáticas da região do Cabo de Santo Agostinho - Pernambuco}

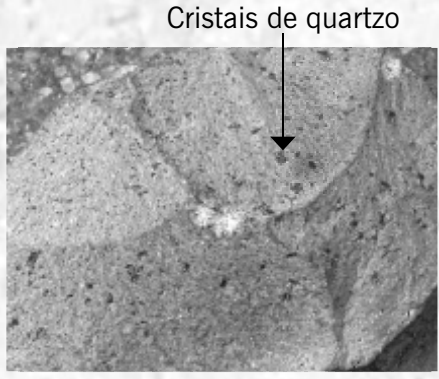

Riolito - rocha vulcânica com pequenos cristais de quartzo e desenvolvimento de fraturas em forma de concha e juntas colunares
Ignimbrito - rocha

vulcanoclástica, formada por

vulcanismo explosivo

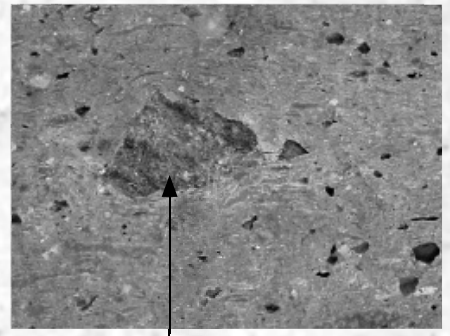

Fragmentos de rochas pré-existentes, que foram atirados ao ar pela explosão que deu origem ao ignimbrito

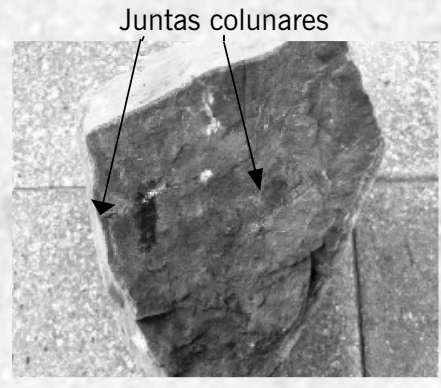

Basalto - rocha vulcânica de coloração escura com desenvolvimento de juntas colunares 


\section{Sugestôes de leitura}

Almeida C. B., Sá E. F. J., Cruz L. R., Nascimento M. A. L. , Alves da Silva F. C. , Antunes A. F., Frutuoso Jr., L. J. ; Lima Filho M. F. ; Souza, Z. S. ,Guedes I. M. G. 2003. A Suíte Magmática Ipojuca: relações e implicações tectono-estratigráficas na Sub-bacia de Pernambuco. In: 2o. Congresso Brasileiro de PED em Petróleo e Gás, Rio de Janeiro. 2o. Congresso Brasileiro de P\&D em Petróleo e Gás, 2003. v. 1. p. Em CD-Em CD.

Almeida F. F. M., Carneiro C. Dal Ré, Mizusaki A. M. P. 1996. Correlação do magmatismo das bacias da margem continental brasileira com as áreas emersas adjacentes. Revista Brasileira de Geociências v. 26(3), p. 125-138.

Amaral A. J. R., Ménor E. de A. 1979. A sequência vulcano sedimentar cretácica da região de Suape $(\mathrm{PE})$ : interpretação faciológica e considerações metalogenéticas. In: $9^{\circ}$ Simpósio de Geologia do Nordeste, Sociedade Brasileira de Geologia, Natal, 1979.

Borba G. S. 1975. Rochas vulcânicas da faixa costeira sul Pernambuco: aspectos petrográficsos e geoquímicos. Dissertação de mestrado, Centro de Ciências Matemáticas e da Natureza, Instituo de Geociências, Rio de Janeiro. 134 P.

Long L. E., Sial A. N., Borba G. S. 1986. Origin of granite at Cabo de Santo Agostinho, Northeastern Brazil. Contribution to Mineralogy and Petrology, v. 92 , p. $341-350$.

Mariano G., Barbosa J. A. 2006. Riolito: o vulcão Pernambucano. In $43^{\circ}$ Congresso Brasileiro de Geologia. Sociedade Brasileira de Geologia, Aracaju, 2006. Anais, P. 38.

Mizusaki A. M. P., Thomaz-Filho A. Milani E. J., Césero P. 2002. Mezozoic and Cenozoic igneous activity and its tectonic control in northeastern Brazil. Journal of South American Earth Sciences v. 159(2) p. 183-198.

Nascimento M. A. L. 2003. Geologia, geocronologia, geoquímica e petrogênese das rochas ígneas cretácicas da província magmática do Cabo e suas relações com as com as unidades sedimentares da bacia de Pernambuco (NE do Brasil). Tese de doutorado, programa de pos-graduação em Geodinãmica e Geofísica, Centro de Ciências Exatas e da Terra, Universidade federal do Rio Grande do Norte.

Nascimento M. A. L., Souza Z. S., Matos R. M. D. 2002.. Evolução magmática da Bacia de Pernambuco, NE do Brasil e sua relação com as rochas sedimentares. In: II Workshop de Avaliação Anual dos PRH's-ANP da UFRN, 2002, Natal. II Workshop de Avaliação Anual dos PRH's-ANP da UFRN, v. 1. p. Em CD.

Nascimento M. A. L. 2005. Potencialidades geoturísticas da região do granito Cabo de Santo Agostinho (NE do Brasil): Meio de promover a preservação do patrimônio geológico. Estudos Geológicos, v. 15, p. 03-14.

Nascimento M. A. L., Souza Z. S., Galindo A. C. 2002. Textura granofírica nas rochas do granito do Cabo de Santo Agostinho, província magmática do Cabo, Bacia de Pernambuco (Nordeste do Brasil): implicações geodinâmicas. Revista de Geologia (UFC), v. 15 p. 101-107.

Nascimento M. A. L., Souza Z. S., Galindo A. C. 2007. Granito do Cabo de Santo Agostinho, PE - único granito conhecido de idade cretácea do Brasil. IN: Winge M., Schobbenhaus C., Berbert-Born M., Queiroz E. T., Campos D. A. (org.) Sítios geológicos e paleontológicos do Brasil. Brasília, v. 2

Nascimento M. A. L., Souza Z. S., Lima Filho M. F. Jardim de Sá E. F., Cruz L. R.,Frutuoso Jr. L. J., Almeida C. B., Antunes A. F., Silva F. C. A., Guedes I. M. G.2004. Relações estratigráficas da Província Magmática do Cabo, Bacia de Pernambuco, Nordeste do Brasil. Estudos Geológicos v. 14 p. 03-19.

Nascimento M. A. L., Souza Z. S., Matos R. M. D 2003. Relações litoestratigráficas entre rochas magmáticas e sedimentares cretáceas na bacia de Pernambuco, Nordeste do Brasil. In: $2^{\circ}$ Congresso Brasileiro de $P$ \& $D$ em petróleo de gás, Rio de Janeiro, v. 1 em CD.

Nascimento M. A. L., Vasconcelos P. M., Souza Z. S, Sá E. F. J., Carmo I. O., Thede D. 2003. 40Ar/39Ar Geochronology of the Cabo magmatic Province, Pernambuco Basin, NE Brazil. IV South American Symposium on Isotope Geology, Salvador, v.4 p. 624-628.

Pfaltzgraff P. A. dos S. 1998. Geologia integrada ao município de Ipojuca/Pernambuco. Recife, CPRM/FIDEM 20p.

Sial A. N., Long L. E., Borba G. S. 1987. Field trip guide excursion: cretaceous magmatic province of Cabo Pernambuco, northest Brazil. Revista Brasileira de Geociências, v. 17 (4), p. 667-673.

Souza Z. S., Vasconcelos P. M., Nascimento M. A. L., Silveira F. V., Paiva H. S., Dias L. G. S., Thede D., Carmo I. O. 2003. 40Ar/39Ar Geochronology of Mesozoic and Cenozoic magmatism in the Brazil. IV South American Symposium on Isotope Geology, Salvador, v.4 p. 691-694. 